\title{
Взаимообусловленность показателей уровня субъективного контроля и эмоциональной сферы игроков командных видов спорта 15-16 лет
}

\author{
Усманова Е.Н. ${ }^{1 *}$, Улъданова Д.Р. ${ }^{2}$ \\ ${ }^{1}$ Поволжская государственная академия физической культуры, спорта и туризма \\ г. Казань, Россия \\ ORCID: oooo-0oo2-4633-20o6, evgeniya-usmanova@mail.ru \\ ${ }^{2}$ Муниципальное автономное учреждение «Спортивная школа №o» \\ г. Набережные Челны, Россия \\ ORCID: oooo-ooo3-0699-6366,e-mail:uldanowa@mail.ru
}

\begin{abstract}
Аннотация: Сохранность спортивного резерва в юношеских командах во многом обеспечивается усилиями тренера по сопоставлению физических изменений $\mathrm{c}$ психологической стороной подготовки, помощью игрокам в разрешении возрастных и ситуационных кризисов, по предупреждению стихийного становления их личности; своевременной ориентацией всех на большой труд во имя будущих побед. Эмоциональная и морально-волевая сфера при этом испытывает колоссальные нагрузки. Цель исследования - выявить особенности проявления субъективного контроля и его взаимосвязь с показателями эмоциональной сферы у игроков командных видов спорта 15-16 лет. Материалы. Протоколы психологической диагностики. Методы исследования. Анализ и обобщение научно-методической литературы, психологическое тестирование (методика диагностики уровня субъективного контроля; опросник для изучения агрессивности личности спортсмена; опросник MBI для выявления «синдрома выгорания»), констатирующий эксперимент, методы математической статистики. Результатъ. Признаки «синдрома выгорания» выявлены у $57 \%$ испытуемых. Интернальный локус контроля отмечается в области достижений у $61 \%$, неудач - у $63 \%$, межличностных отношений - 66\%; в наименьшей степени проявляется в семейных (34\%) и производственных (20\%) отношениях. В среднем по выборке индекс агрессивности $\left(U_{\text {aгр }}=57,8\right)$ выше индекса враждебности $\left(И_{\text {вр }}=48,9\right)$. При этом 14 игроков-экстерналов, подчас не справляясь с негативными эмоциями, имеют склонность испытывать глубинное чувство вины вместо чувства ответственности в социально и лично значимых ситуациях. Заключение. Юноши с интернальным типом самоконтроля в шесть раз реже испытывают эмоциональное истощение, втрое реже проявляют цинизм по отношению к товарищам по команде, хотя имеют некоторую склонность редуцировать (обесценивать) значимость своих личных достижений на фоне все возрастающих требований нового уровня спортивных результатов. Спортсмены-интерналы в два раза реже склонны испытывать чувство вины, отдавая предпочтение принятию объективной ответственности в сфере межличностных, семейных и производственных отношений, в ситуации достижений или неудач.

Ключевые слова: уровень субъективного контроля, эмоциональное выгорание, индекс агрессивности и враждебности, чувство вины, чувство взрослости, игровые виды спорта, юные спортсмены.
\end{abstract}

Для цитирования: Усманова Е.Н.*, Ульданова Д.Р. Взаимообусловленность показателей уровня субъективного контроля и эмоциональной сферы игроков командных видов спорта 15-16 лет. Педагогико-психологические и медико-биологические проблемы физической культуры и спорта.2020 15(4): 78-83. DOI: 10.14526/2070-4798-2020-15-4-78-83

\section{Interconditionality of subjective control level indices and emotional sphere of 15-16 year-old team sports players}

Evgeniya N. Usmanova ${ }^{1 *}$, Dinara R. Uldanova ${ }^{2}$

${ }^{1}$ VolgaregionStateAcademyofPhysicalCulture, Sport and Tourism

Kazan, Russia

ORCID: oooo-ooo2-4633-20o6, evgeniya-usmanova@mail.ru* 


\title{
${ }^{2}$ Municipal Autonomous Establishment "Sports school №10" Naberezhnye Chelny, Russia \\ ORCID: oooo-ooo3-0699-6366,e-mail: uldanowa@mail.ru
}

\begin{abstract}
Sports reserve preservation in youth teams is mainly conditioned by the efforts of a coach connected with physical changes correlation with psychological side of training, by the help in dealing with age related and situational crises, in order to prevent spontaneous formation of their personality; by timely orientation toward work for the sake of the future success. In this case emotional and moral-volitional spheres experience great loads. The aim of the research is to reveal the peculiarities of subjective control and its connection with emotional sphere indices among 15-16 year-old players of team sports. Materials. Protocols of psychological diagnostics. Research methods. Information sources analysis and summarizing, psychological testing (methodology of subjective control level diagnostics; questionnaire for an athlete's aggressiveness level study; MBI questionnaire for "burnout syndrome" revelation), stating experiment, methods of mathematical statistics. Results. The features of "burnout syndrome" were revealed among $57 \%$ of respondents. Internal locus of control is mentioned in the progress field among $61 \%$ of respondents, in the field of failures - among $63 \%$, interpersonal relations-66\%; least of all it is revealed in family (34\%) and industrial (20\%) relations. In the average according to sampling aggressiveness index $\left(I_{\text {agr }}=57,8\right)$ is higher than hostility index $\left(I_{h o}=48,9\right)$. At the same time 14 playersexternals, who very often can't deal with their negative emotions, show the tendency to experience deep sense of guilt instead of sense of responsibility in socially and personally important situations. It proves that adolescent crisis is not solved and creates considerable psycho-emotional tension, prevents age-related and sports crises productive solution [4]. Conclusion. Young men with an internal type of self-controlsix times less experience emotional exhaustion, three times less show cynicism towards team members, though they have some tendency to reduce (depreciate) the importance of own personal achievements on the basis of the increasing demands of a new level of sports results. Athletes-internals twice less experience sense of guilt, preferring objective responsibility in the sphere of interpersonal, family and industrial relations, in the situation of success or failure.
\end{abstract}

Keywords: level of subjective control, emotional burnout, aggressiveness and hostility index, sense of guilt, sense of being adult, team sports, young athletes.

For citation: Evgeniya N. Usmanova*, Dinara R. Uldanova. Interconditionality of subjective control level indices and emotional sphere of 15-16 year-old team sports players. Russian Journal of Physical Education and Sport. 2020; 15(4): 78-83. DOI: 10.14526/2070-4798-2020-15-4-78-83

\section{АКТУАЛЬНОСТЬ}

В 15-16 лет одной из общих возрастных особенностей юного футболиста (или представителей других командных игровых видов спорта) является потребность в самоутверждении.И основывается она преимущественно на достижениях в тренировочном процессе приудовлетворении ипроявлении морально-волевых усилий. Происходит активное развитие социального интеллекта, формируется про активное мышление, проявляющееся в рациональных и ресурсных формах поведения, в условиях стрессов соревновательной и общественной жизни[1].Спортсмены в этом возрасте проживают так называемый юношеский кризис самоопределения, связанный с решением жизненно важного вопроса о профессиональной и нравственной самоидентификации. Задача и моральный долг тренера - увязать физические изменения с психологической стороной подготовки, предупредить стихийной становление личности игроков; сориентировать всех на будущий большой труд $[2,3]$.

Однако разрешению противоречия кризиса юношеского возраста (между «должен (выбрать свою карьеру, жизнь), но не хочу (ошибиться)») предшествует успешное разрешение каждым спортсменом противоречия подросткового кризиса («хочу (быть взрослым), но (пока) не могу») и усвоение «чувства взрослости» через осознание ответственности за себя и свои поступки (см. рисунок 1) [4,5]. 


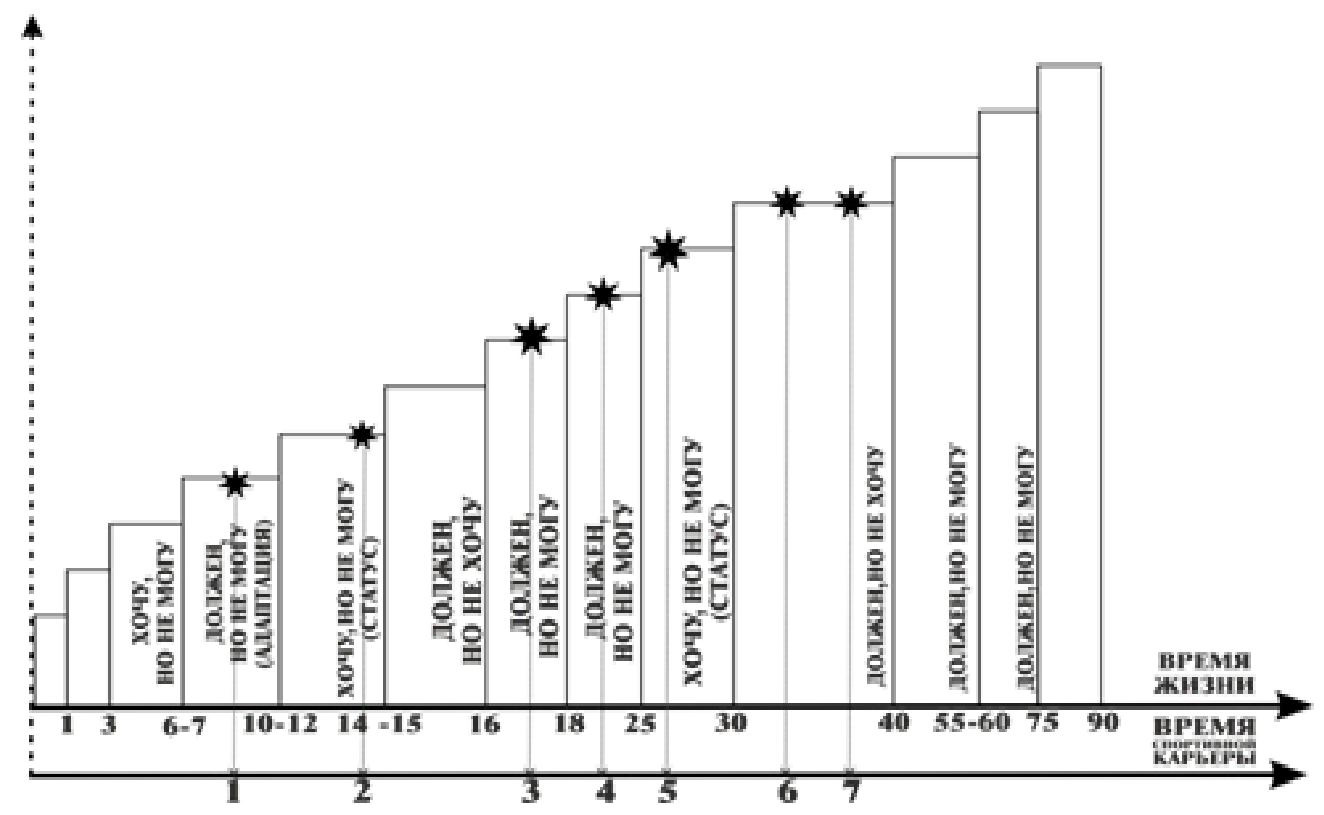

Рисунок. 1. Кризисная модель жизни и спортивной карьеры

Кризисы-переходы спортивной карьеры: 1-начало спортивной специиализации; 2 -переход к углубленной тренировке; 3 -переход из массового спорта в спорт высших достижений; 4 -переход из юношеского спорта во взросльй спорт; 5 -переход из любительского спорта в профессиональный спорт; 6 -nереход от кульминации к финишу спортивной карьеры; 7 -завершение спортивной карьеры и переход к другой карьере.

В противном случае, как отмечают тренеры в своей практике, игрок начинает соглашаться со всеми объективными доводами, но продолжает играть и поступать по-своему. Зачастую это приводит к конфликту интересов и ролевых позиций между тренером и игроком, игроком и командой и в конечном счете значительно сказывается на сохранности спортивного резерва на переходных этапах спортивной карьеры в целом $[4,5]$.

Поиск ответа на вопрос о том, всегда ли спортсмены юношеского возраста, вовлеченные в занятия командными спортивными играми на регулярной основе, демонстрируют высокие показатели интернального типа субъективного контроля, свидетельствующего, по сути, о своевременном преодолении подросткового возрастного кризиса и усвоении «чувства взрослости», обусловил постановку цели предлагаемого исследования.

Цель исследования - выявить особенности проявления субъективного контроля и его взаимосвязь с показателями эмоциональной сферы у игроков командных видов спорта 15-16 лет.

\section{МАТЕРИАЛЫ И МЕТОДЫ}

В исследовании принял участие 41 спортсмен 15-16 лет (32 футболиста и 9 баскетболистов). Данные спортсмены в предсоревновательном мезоцикле 2018-2019 учебного года ответили на вопросы трех диагностических методик:

1 -методика диагностики уровня субъективного контроля (Дж. Роттер в адаптации Е.Ф. Бажина, Е.А. Голынкиной, А.М.Эткинда, 1984); 2 - опросник для изучения агрессивности личности спортсмена (А. Басс, А. Дарки в адаптации А.К. Осницкого, 1999);

3 -опросник МВI для выявления «синдрома выгорания» (К. Маслач и С.Джексона в адаптации Н.Е.Водопьяновой, 2000).

\section{РЕЗУЛЬТАТЫ И ОБСУЖДЕНИЕ}

Анализ результатов по опроснику «синдром выгорания» показал наличие признаков выгорания у 57\% испытуемых, в том числе по одному компоненту у $23 \%$ спортсменов, по двум - у 27\%, трем компонентам - у $7 \%$ респондентов.

Анализ результатов локуса контроля 
по основным сферам жизни показал, что преимущественно спортсмены

данной

выборки осознают себя ответственными в ситуациях, связанных со своими достижениями (61\%), неудачами (63\%), и в межличностных отношениях (66\%). В наименьшей степени интернальный тип самоконтроля проявляется ими в семейных (34\%)и производственных (20\%) отношениях.

Описательные характеристики данной выборки спортсменов-игровиков 15-16 лет на основе локализации субъективного контроля представлены в таблице 1.

Таблица 1 - Локализация субъективного контроля и показатели эмоциональной сферыу спортсменов-игровиков 15-16 лет, $\mathrm{n}=41$

\begin{tabular}{|c|c|c|c|c|c|c|c|c|c|c|c|c|c|}
\hline \multirow{2}{*}{$\begin{array}{l}\text { Локализация } \\
\text { субъективного } \\
\text { контроля }\end{array}$} & \multicolumn{7}{|c|}{ Переменные опросника УСК } & \multicolumn{3}{|c|}{$\begin{array}{l}\text { Переменные } \\
\text { опросника } \\
\text { «Эмоциональное } \\
\text { выгорание» }\end{array}$} & \multicolumn{3}{|c|}{$\begin{array}{l}\text { Переменные } \\
\text { опросника } \\
\text { А.Басс, А.Дарки }\end{array}$} \\
\hline & $\begin{array}{l}\text { Ио, } \\
\text { чел }\end{array}$ & $\begin{array}{l}\text { Ид, } \\
\text { чел }\end{array}$ & $\begin{array}{l}\text { Ин, } \\
\text { чел }\end{array}$ & $\begin{array}{l}\text { Ис, } \\
\text { чел }\end{array}$ & $\begin{array}{l}\text { Ип, } \\
\text { чел }\end{array}$ & $\begin{array}{l}\text { Им, } \\
\text { чел }\end{array}$ & $\begin{array}{l}\text { Из, } \\
\text { чел }\end{array}$ & $\begin{array}{l}\text { ЭИ, } \\
\text { чел }\end{array}$ & $\begin{array}{l}\text { Д, } \\
\text { Чел }\end{array}$ & $\begin{array}{l}\text { РЛД, } \\
\text { чел }\end{array}$ & $\begin{array}{l}\text { ЧВ, } \\
\text { чел }\end{array}$ & $\begin{array}{l}\text { Иагр, } \\
\text { Сред }\end{array}$ & $\begin{array}{l}\text { Ивр, } \\
\text { сред }\end{array}$ \\
\hline Интерналы & 13 & 25 & 15 & 14 & 8 & 26 & 27 & 2 & 4 & 4 & 7 & 54,5 & 45,7 \\
\hline Экстерналы & 28 & 16 & 26 & 27 & 33 & 15 & 15 & 12 & 12 & 7 & 16 & 59,3 & 50,7 \\
\hline
\end{tabular}

Интернальность по всем семи шкалам была отмечена только у 3 спортсменов данной выборки. Остальные спортсмены показали выборочную интренальность в основных сферах жизни. Поэтому для дальнейшего анализа диагностических данных мы условно разделили группу респондентов на интерналов и экстерналов исходя из результатов по шкале «общая интернальность».

В среднем по выборке индекс агрессивности ( $\left.{ }_{\text {агр }}\right)$ составил 57,8(ФА+ВА+КА/3) и превысил индекс враждебности (И вр), который составил48,9 $(\mathrm{H}+\mathrm{P}+\Pi+\mathrm{O} / 4)$. Числовой показатель «чувство вины» рассматривался как уровень аутоагрессии спортсмена в том случае, если он превышал $И_{\text {агр }}$ и $И_{\text {вр }}$ и как нравственный регулятор спортсменов данной выборки, если не превышал. Соотношение по данному показателю составило 34\% к 66\% соответственно. Тоесть, 14 спортсменов (преимущественно с экстернальным типом самоконтроля) склонны испытывать чувство вины вместо чувства ответственности в социально и лично значимых ситуациях. Это, в свою очередь, может свидетельствовать о не разрешении подросткового кризиса, создавать значительное психо-эмоциональное напряжение на пути преодоления последующих возрастных и спортивных кризисов, приводить к профессиональному выгоранию.

Для установления

\section{и направленности}

взаимосвязей между

корреляционных $\begin{array}{llll}\text { контроля } & \text { и }\end{array}$ сферы были отобраны 13 переменных: 7 из них относятся к интернальности (общей $\left(И_{о}\right)$, в области достижений(И), неудач $\left(И_{\text {н }}\right)$, семейных (Ис), производственных $\left(И_{\Pi}\right)$, межличностных (Й $)$ отношений, $\left(И_{3}\right)-$ здоровья/болезни),3 переменные относятся к «синдрому выгорания» (эмоциональное истощение (ЭИ), деперсонализация (цинизм) (Д), редукция личных достижений (РЛД)) и 3 переменные(чувство вины (ЧВ), индекс агрессивности $\left(И_{\text {агр }}\right)$, индекс враждебности $\left(И_{\text {вр }}\right)$ - к исследованию форм проявления агрессии у спортсменов выборки. Результаты корреляционного анализа представлены таблице 2.

Установлена преимущественно отрицательная взаимосвязь между шкалами интернальности и компонентами выгорания «ЭИ» и «Д». Чем выше общая интернальность, тем ниже показатели «синдрома выгорания». Исключение составил показатель «РЛД». Чем выше интернальность в области достижений, тем заметнее спортсмены склонны занижать значимость своих достижений и тем самым предупреждать развитие негативных черт личности, таких как «звездная болезнь», высокомерие.

Чем выше интернальность в области 
межличностных отношений, тем вероятнее проявление эмоционального истощения и цинизма в отношении партнеров по команде, возможно проявление агрессии, что в целом характерно длянеоднородного по индивидуальным психологическим характеристикам юношеского спортивного коллектива и его высокой интенсивности взаимодействия в процессе игры.
Переменная «ЧВ» имеет отрицательную взаимосвязь между всеми переменными интернальности и положительную взаимосвязь со всеми переменными «синдрома выгорания» и агрессивности. То есть, чем больше спортсмен проявляет интернальный тип самоконтроля (ответсвенность), тем меньше он испытывает чувство вины и признаки «синдрома выгорания».

Таблица 2 - Теснота и направленность корреляционных взаимосвязей между переменными локуса контроля, «синдрома выгорания», агрессивности у игроков 15-16 лет

\begin{tabular}{|c|c|c|c|c|c|c|c|c|c|c|c|c|c|}
\hline Перем енные & Иo & Ид & $\mathrm{YH}_{\mathrm{H}}$ & $\mathrm{Kc}_{\mathrm{c}}$ & Ип & Им & Иs & पB & $Э \mathrm{Y}$ & I & РЛД & Иarp & Ивр \\
\hline Иo & 1 & & & & & & & & & & & & \\
\hline Й & 0.46868 & 1 & & & & & & & & & & & \\
\hline $\mathrm{KH}_{\mathrm{H}}$ & 0.66364 & 0.06163 & 1 & & & & & & & & & & \\
\hline Иc & 0.39981 & 0.26235 & 029306 & 1 & & & & & & & & & \\
\hline Иn & 0,27895 & 0,25922 & 0,17161 & 0,07268 & 1 & & & & & & & & \\
\hline Им & 0,54268 & 0,35778 & 0,34218 & $-0,1737$ & 0,1335 & 1 & & & & & & & \\
\hline Иs & 0.28962 & -0.1738 & 0.08495 & 0.06157 & -0.2045 & -0.1249 & 1 & & & & & & \\
\hline पB & -0.2931 & -0.1814 & -0.1484 & -0.1383 & -0.1154 & -0.2492 & 0.03513 & 1 & & & & & \\
\hline$Э \mathrm{Y}$ & $-0,3669$ & -0.2829 & -0.2247 & -0.3488 & -0.2641 & 021206 & -0.1056 & 0.1901 & 1 & & & & \\
\hline I & $-0,2261$ & $-0,1962$ & $-0,1533$ & $-0,2007$ & $-0,4788$ & 0,1928 & $-0,1641$ & 0,0977 & 0,6427 & 1 & & & \\
\hline РлI & 0,09995 & 0,4026 & $-0,0336$ & $-0,2103$ & 0,1378 & 0,3432 & $-0,1048$ & 0,0017 & 0,1749 & $-0,0958$ & 1 & & \\
\hline Иarp & -0.2364 & -0.1496 & \begin{tabular}{|l|}
-0.2442 \\
\end{tabular} & -0.2451 & -0.1292 & 0.07389 & -0.1281 & 0.1499 & 0.5909 & 0.54882 & -0.1176 & 1 & \\
\hline Ивp & -0.2061 & -0.1562 & $-0,098$ & -0.1258 & -0.3095 & 0.04138 & -02144 & 0.1875 & 0.4686 & 0.49398 & 0.01732 & 0.6354 & \\
\hline
\end{tabular}

\section{ЗАКЛЮЧЕНИЕ}

Таким образом, можно констатировать, что юноши с интернальным типом самоконтроля в шесть раз реже испытывают эмоциональное истощение, втрое реже склонны проявлять цинизм по отношению к товарищам по команде, хотя имеютнекоторую склонность обесценивать (редуцировать) значимость своих личных достижений на фоне все возрастающих требований нового уровня спортивных результатов.

Также такие спортсмены в два раза реже склонны испытывать чувство вины, отдавая предпочтение принятию объективной ответственности в сфере межличностных, семейных ипроизводственных отношений, в ситуации достижений или неудач. Проявление агрессивного поведения у них носит скорее инструментальный характер в формате «спортивной злости» или «праведного гнева», нежели враждебности как самоценности при взаимодействии с внешним миром, чувство вины у нихвыступает регулятором социального поведения как нравственная составляющая личности.

Однако тот факт, что игроки с интернальным типом самоконтроля в данной выборке составили лишь 31\%, свидетельствует о важности и необходимости целенаправленной работы тренерского штаба по формированию и воспитанию спортивного коллектива как малой социальной группы, с применением индивидуально-дифференцированного и ресурсного подходов.

\section{СПИСОК ЛИТЕРАТУРЫ}

1. Горская, Г. Б. Психологические ресурсы преодоления долговременных психических нагрузок на разных этапах профессиональной карьеры спортсменов командных видов спорта / Г. Б. Горская,3.Р. Совмиз // Физическая культура и спорт - наука и практика. - 2018. - №3. - С.88-93.
2. Горская,
Г.Б.
Динамический 
анализ психологических ресурсов конкурентоспособности спортсменов / Г.Б. Горская // Ресурсы конкурентоспособности спортсменов: теория и практика реализации. 2018. - № 1. - С. 64-66.

Кузнецов, А. С. Анализ психологических и физиологических показателей спортсменов разной специализации на этапах преодоления возрастных и карьерных кризисов спортивной деятельности / А. С. Кузнецов, Е.Н.

Усманова,О.В.Коломыцева // Материалы

Первой международной Поволжской конференции по экономике, гуманитарным наукам и спорту (FICEHS 2019) DOI: https:// doi.org/10.2991/aebmr.k.200114.213.

3. Яковлев, Б.П. Эмоциональная напряжённость в условиях спортивной подготовки квалифицированных спортсменов / Б.П. Яковлев, А.В. Прибега, И.В. Корчмарь // Здоровье человека, теория и методика физической культуры и спорта. - 2018. - № 1(8). - С. 110-124.
4. Кузнецов А.С., Усманова Е.Н., Коломыцева О.В. Исследование психологофизиологических показателей спортсменов различных специализаций на этапах преодоления кризисов спортивной карьеры. Педагогико-психологические и медикобиологические проблемы физической культуры и спорта. 2019; 14(2): 89-96. DOI: 10.14526/20704798-2019-14-2-89-96.

5. Eysenck M.W., Derakshan N., Santos R., Calvo M.G. Anxiety and cognitive performance: Attentional control theory. Emotion. 2007; 7: 336353 .

6. Frederickson B.L. Positive emotions and upward spirals in organizations. Positive organizational scholarship: Foundations of a new discipline. 2003: 163-175.

7. Graham T.R., Kowalski K.C., Crocker P.R.E. The contributions of goal characteristics and causal attributions to emotional experience in youth sport participants. Psychology of Sport and Exercise. 2002; 3: 273-291.

\section{Статья поступила в редакцию: 12.11.2020}

Усманова Евгения Николаевна - кандидат педагогических наук, стариий преподаватель, Поволжская государственная академия физической культуры, спорта и туризма, 420138, Россия, г. Казань, ул. Деревня Универсиады, дом 35, e-mail: evgeniya-usmanova@mail.ru

Ульданова Динара Равильевна - тренер 1 категории по баскетболу, Муниципальное автономное учреждение«Спортивная школа №10», 423808, Россия, г. Набережные Челны, ул. Комарова, дом 23, e-mail: uldanowa@mail.ru 